\title{
Difficulties in Emotional Regulation and Risky Driving Among Lithuanian Drivers
}

Laura Šeibokaitè, Auksè Endriulaitienè, Mark J.M. Sullman, Rasa Markšaitytè, and Kristina Žardeckaitè - Matulaitienè

\section{INTRODUCTION}

The World Health Organization (2015) highlights the urgent need to concentrate on resolving the global public health issue that is road safety. Road fatalities are a particularly large concern in low and middle-income countries, where more than 90 percent of the world's car crashes occur (World Health Organization 2009). Lithuania is a middle-income Eastern European country that has one of the highest traffic injury and fatality rates in Europe (Eurostat 2015).

One of the most commonly studied causes of traffic accidents is risky driving behaviour (Di Stasi et al. 2010; Hu et al. 2013; Roidl et al. 2013; Trógolo et al. 2014). Researchers agree that psychological factors are related to risky driving and thus contribute, or detract, from traffic safety. Surprisingly psychological factors have rarely been studied in Lithuania or any other Post-Soviet countries in relation to road safety. Therefore, data from this region would improve our understanding of the traffic safety problem, which would also be valuable for other small and lower income countries.

Risky driving has been described in the literature as any actions that increase the likelihood of a crash or the severity of injury if a crash occurs (Reason et al. 1990). This definition includes behaviours such as: speeding, tailgating, running red lights, weaving across lanes, and other behaviours caused by inattention (Dula and Geller 2003; Lajunen et al. 2004). Although researchers use a number of different terms to describe driver behaviour (e.g. aberrant driving, dangerous driving, and aggressive driving) in this paper the term risky driving was chosen as this most accurately reflects the self-reported driving behaviours measured in this study.

An extensive body of research has found four types of risky driving - lapses, errors, ordinary violations, and aggressive violations (e.g. Mesken et al. 2002; Özkan et al. 2006b; Sullman et al. 2002). Lapses can be described as "the unwitting deviation of action from intention" (Reason et al. 1990, p. 1315), while errors are "the departure of planned actions from some satisfactory path towards a desired goal" (Reason et al., p. 13151316). Ordinary violations are usually defined as "deliberate infringements of the 'rules of the road', rules that are often unwritten and informal" (Mesken et al. 2002, p.471), while aggressive violations "involve aggressive behaviours directed towards another road user" (Mesken et al. 2002, p.471).

Among the many factors which are related to risky driving (e.g., personality traits, attitudes, motives), emotions have been found to play an important role (Hu et al. 2013; Rhodes et al. 2015; Nesbit and Conger 2012). Research findings support the idea that negative emotions, as well as positive emotions, can deteriorate the quality of driving performance (Hu et al. 2013; Jallais et al. 2014; Jeon et al. 2014; Mesken 2006; Rhodes at al. 2015).

Still, these findings do not naturally lead to specific interventions. As there is little possibility to avoid emotions in everyday life, an individual's ability to deal with emotions may be of considerable importance in the driving context (Trógolo et al. 2014). However, research exploring the relationship between emotion regulation and risky driving, self-reported or simulated, is scarce (Arnau-Sabatés et al. 2012). In terms of other types of problem behaviours, emotion regulation has been investigated much more intensively. For example, poor emotion regulation skills have also been found to predict alcohol use during and after treatment among a sample of alcohol dependant patients (Berking et al. 2011). Furthermore, adaptive stress coping strategies have been found to be a protective factor for non-suicidal self-injury in young people (Williams and Hasking, 2010). 
These findings together confirm the important role emotion regulation skills play in maladaptive behaviour and provide the rationale to expect an association between self-reported risky driving and difficulties with emotion regulation.

Gratz and Roemer (2004) proposed a model of emotion regulation which is based on emotional responses. Emotion regulation can be defined as a set of different, but interrelated abilities, including: emotional awareness, emotional clarity, emotional acceptance, impulse control, the ability to engage in desired goals while experiencing negative emotions and the ability to use flexible and appropriate strategies to modulate emotional responses (Trógolo et al. 2014, p. 109). A shortage or absence of these skills would describe the presence of difficulties in emotion regulation. Lack of emotional awareness reflects an inattention to, and lack of awareness of emotional responses. Lack of emotional clarity reflects the extent to which individuals know (and are clear about) the emotions they are experiencing. Non-acceptance of emotional responses reflects a tendency to have negative secondary emotional responses to one's negative emotions, or not accepting reactions to one's distress. Impulse control difficulties reflect difficulties remaining in control of one's behaviour when experiencing negative emotions. Difficulties engaging in goal-directed behaviour reflects difficulties in concentrating and accomplishing tasks when experiencing negative emotions. Limited access to emotion regulation strategies reflects the belief that there is little that can be done to regulate emotions effectively, once an individual is upset (Gratz and Roemer 2004, p. 47).

Several studies in a risky driving context have revealed relatively consistent results, in that adolescents identified as lacking the ability to identify and describe feelings, and to distinguish these from somatic sensations, have a higher risk of motor vehicle accidents (Cerniglia et al. 2015). Furthermore, Arnau-Sabatés et al. (2012) reported that a positive attitude towards risky driving was negatively correlated with emotional abilities. When encouraged to reappraise frustrating events, under experimental conditions, drivers performed better than those who were not using any type of emotion regulation strategy (Harris and Nass 2011). Using the model of Gratz and Roemer (2004), Trógolo et al. (2014) confirmed that lower difficulties in emotional regulation were related to more adaptive, careful driving, whereas higher difficulties lead to more risky or angry driving. After controlling for possible interactions between the different abilities in emotion regulation, nonacceptance of emotional responses, lack of emotional awareness and impulse control difficulties had the highest predictive values regarding various dangerous driving styles (Trógolo et al. 2014).

In spite of the quantity of research supporting the important role emotion regulation plays in driving behaviour, there is a lack of research in different cultural contexts. The expression of emotions and the acceptance of emotional expression in societies differs quite widely between countries and cultures (Mesquita and Walker 2003). Butler et al. (2007) provide evidence that people from Western cultures are less inclined to suppress negative emotions than those from an Eastern culture, due to different social consequences. Similarly, cross-cultural differences have also been found for risky driving. For example, research has found that drivers from Southern European and Middle Eastern countries report higher levels of driving errors and aggressive violations, than drivers from Western and Northern Europe (Özkan et al. 2006a). However, further research in more diverse countries is needed, as both risky driving and emotion regulation are sensitive to the social context. The purpose of this study was to investigate the relationship between difficulties in emotion regulation and selfreported risky driving behaviour in the sample of Lithuanian drivers. Based on the literature, we hypothesized that difficulties in emotion regulation would be positively correlated with self-reported risky driving 
(operationalized by driving errors, lapses, aggressive violations, and ordinary violations, see Lajunen et al. 2004). However, as driving errors and lapses have a different psychological origin to that of violations (Lajunen and Özkan 2011), we would also expect their relationships with emotional regulation to differ.

In addition, as well emotion regulation, gender differences are also important to include when studying risky driving. There is an extensive body of research which has reported males have a higher propensity towards risk taking on the road than females (González-Iglesias et al. 2012; Rhodes and Pivik 2011; Sullman and Taylor 2010; Taubman - Ben-Ari 2012). Research has also reported that men have greater difficulties in dealing with emotions than women (Gratz and Roemer 2004; McRae et al. 2008). Therefore, we hypothesised that there would be significant gender effects in the relationship between risky driving and emotion regulation.

\section{METHOD}

\section{Participants}

In total, 246 non-professional Lithuanian drivers volunteered to participate in the study. The group was comprised of 117 males and 129 females (all Caucasians), who ranged from 19 to 75 years old (M = 36.66, SD =11.45). Previous research has confirmed a strong relationship between age and experience (e.g. Sullman et al. 2002). Therefore, although we did not measure driving experience directly, the majority of the sample is likely to be experienced drivers (21.5 percent of participants were 19-25 years old, 43.1 percent were 26-40 years old, 32.4 percent were 41-59 years old, 3 percent were 60-75 years old). In comparison to the general population of drivers in Lithuania, this sample is slightly over-represented by younger drivers and under-represented by elderly. Official statistical data show that 12.3 percent of Lithuanian drivers are 19-25 years old, 35.06 percent are 26-40 years old, 39.28 percent are 41-59 years old, and 13.36 percent are 60-75 years old (data received from SE Regitra on special request). In order to be included in the study, participants had to hold a valid drivers' licence and to drive regularly. If a participant reported he/she seldom drove or drove occasionally, they were excluded from the study. Questionnaires were distributed by research assistants using convenience sampling. Friends, family and colleagues of the researchers were approached, informed about the research and asked to participate. No personal details were collected which could allow the identification of the participant. Respondents were told that the study aimed to analyse the relationship between emotional reactions and driving behaviour. They were all assured that the results would only be used for scientific purposes and that all information provided was completely confidential and anonymous. Those who agreed to participate were given a hardcopy of the questionnaire and were asked to complete the survey at their convenience. A few days later the completed questionnaire was returned to a research assistant in a sealed envelope. The researchers who analysed the data could not associate any of the questionnaires with particular individuals, which was undertaken in order to minimise response and social desirability bias.

\section{Instruments}

Difficulties in emotion regulation were assessed using a Lithuanian version of the Difficulties in Emotion Regulation Scale, DERS (Gratz and Roemer 2004). This 36-item self-report instrument measures difficulties in six regulatory abilities: Lack of emotional awareness (6 items, e.g. "I am attentive to my feelings"), Lack of emotional clarity (5 items, e.g. "I have difficulty making sense out of my feelings“), Non-acceptance of 
emotional responses (6 items, e.g. "When I'm upset, I feel guilty for feeling that way“), Difficulties engaging in goal-directed behaviour (5 items, e.g. "When I'm upset, I have difficulty concentrating"), Impulse control difficulties (6 items, e.g. "When I'm upset, I lose control over my behaviors“), and Limited access to emotion regulation strategies (8 items, e.g."When I'm upset, I believe that I'll end up feeling very depressed"). Study participants were asked to indicate how often items applied to them using a five point Likert scale (1 - "almost never" to 5 - "almost always), with a higher score on each sub-scale indicating more regulation difficulties. The back - forward translation procedure was conducted in order to prepare the questionnaire for use in a Lithuanian sample.

The internal consistencies were good for all subscales: Lack of emotional awareness (Cronbach alpha $=.677$ ), Lack of emotional clarity (Cronbach alpha $=.740)$, Non-acceptance of emotional responses (Cronbach alpha $=$ .814), Difficulties engaging in goal-directed behaviour (Cronbach alpha $=.833$ ), Impulse control difficulties $($ Cronbach alpha $=.846)$, Limited access to emotion regulation strategies $($ Cronbach alpha $=.740)$. The DERS has been found to have good test-retest reliability, as well as construct and predictive validity (Gratz and Roemer 2004; Lavender et al. 2015), but research on the validity of the scale in Lithuania is still in progress.

Risky driving behaviour was measured using the Manchester Driver Behaviour Questionnaire (DBQ) (Lajunen et al. 2004), which was also translated into Lithuanian using the back - forward translation procedure. The DBQ is the most commonly used framework for investigating risky driving behaviour and has substantial evidence of scale reliability and validity (e.g. Mesken et al. 2002; Stelmokienè et al. 2013; Sullman et al. 2002). The DBQ asks respondents to indicate how often they engage in each of the 28 types of risky driving behaviour. Answers are recorded on a six point Likert scale, which ranges from 1 - "never" to 6 - "nearly all the time". The DBQ yields four types of self-reported driving behaviour - Lapses ( 8 items, Cronbach alpha $=.737$, e.g. "Hit something when reversing that you had not previously seen"), Errors ( 8 items, Cronbach alpha $=.780$, e.g. "Brake too quickly on a slippery road"), Aggressive violations (3 items, Cronbach alpha = .764, e.g. "Sound horn to indicate your annoyance“), and Ordinary violations ( 8 items, Cronbach alpha $=.856$, e.g. "Disregard speed limit on a residential road"). A higher score on each sub-scale indicates a stronger tendency to engage in each type of risky driving behaviour.

\section{RESULTS}

The Kolmogorov - Smirnov test revealed that all scales differed significantly from normal distribution (value ranged from .06 to .21, p<.05), but skewness and kurtosis values all ranged from minus one to one (skewness value ranged from .08 to .93 , kurtosis value ranged from .24 to .69), except for aggressive violations (skewness 1.3 and kurtosis 1.4). Logarithmic transformations were used to transform the aggressive violations, which resulted in acceptable skewness and kurtosis values (skewness .55 and kurtosis .76), meaning that parametric statistics could be used for all analyses.

Table 1 presents the descriptive statistics and gender differences. Males scored higher on the aggressive violations and ordinary violations scales. In contrast, only two of the six emotion regulation subscales had gender differences. Females scored significantly higher on the non-acceptance of emotional responses, but males reported greater emotional awareness problems than females. Due to the significant gender differences for several of the variables, gender was controlled for in all following analyses. Furthermore, several of the variables had small correlations with age. Specifically, ordinary violations was negatively related to age ( $\mathrm{r}=-.17$; 
$\mathrm{p}=.006)$ and non-acceptance of emotional responses was positively related to age $(\mathrm{r}=.13 ; \mathrm{p}=.045)$. Due to these statistically significant correlations age was included as a control variable in the final model.

\section{[Insert Table 1 here]}

Correlational analyses revealed many significant associations between risky driving and difficulties with emotion regulation, although there were slight differences between male and female drivers (Table 2). Difficulties engaging in goal-directed behaviour, impulse control difficulties, limited access to emotion regulation strategies, and a lack of emotional clarity were positively related to all types of risky driving behaviour in males. However, among males only errors and lapses had significant positive correlations with the non-acceptance of emotional responses and a lack of emotional awareness was not related to any type of risky driving behaviour. Lapses and errors correlated positively with all scales of emotion regulation difficulties in females. Impulse control difficulties and a lack of emotional awareness both had positive correlations with all four types of risky driving behaviour. Furthermore, ordinary violations were found to be significantly related to difficulties engaging in goal-directed behaviour and a lack of emotional awareness.

\section{[Insert Table 2 here]}

Structural equation modelling was used in order to control for the intercorrelations among the variables and to create a comprehensive model. The four types of risky driving were chosen as dependent variables and gender, age, and emotion regulation difficulties were selected as independent variables. The model presented in Figure 1 had good fit indices: Chi square $=19.341, \mathrm{df}=18, \mathrm{p}=.371 ; \mathrm{CFI}=.999 ; \mathrm{RMSEA}=.017$. Covariations among difficulties of emotion regulation and covariations among risky driving components were introduced into the analysis, but are deleted from the figure for improved clarity. Also, a lack of emotional clarity and a lack of emotional awareness were omitted from the final model, as these problems were not related to any type of risky driving behaviour.

\section{[Insert Figure 1 here]}

The results show that the non-acceptance of emotional responses explains higher lapse scores, but were related to lower aggressive violations and ordinary violations scores. Impulse control difficulties were related to higher scores for errors, aggressive and ordinary violations, while difficulties engaging in goal-directed behaviour was associated with higher scores for lapses, aggressive violations and ordinary violations. Limited access to emotion regulation strategies had a negative relationship with ordinary violations, but a positive relationship with errors.

In summary, the correlational analysis and structural equation modelling revealed several different results. Specifically, the non-acceptance of emotional responses had no significant relationship with violations in the correlational analysis, but had a significant negative association with violations in the integrated model. Furthermore, limited access to emotion regulation strategies was positively correlated with violations in men, 
while the correlation was not significant amongst women. However, in the integrated model the relationship between these variables became negative.

\section{DISCUSSION}

Previous research has highlighted the importance of emotions in risk-taking behaviour (Arnau-Sabatés et al. 2012), but relatively little research has examined the relationship with risky driving behaviour and none has been conducted in Lithuania. The aim of the present investigation was to explore the relationship between emotion regulation difficulties and self-reported risky driving behaviour in a sample of Lithuanian drivers.

The results revealed several gender differences. As reported in earlier research, male drivers reported more aggressive and ordinary violations than females (González-Iglesias et al. 2012; Taubman - Ben-Ari 2012). Gender differences in driving have been explained by different sex-roles (Sullman et al. 2016), higher social acceptance of male risk taking by society and an evolutionary based gender identity (Özkan and Lajunen 2006). Similar to Gratz and Roemer (2004), we found that women had less difficulty, than men, with emotional awareness. Studies on the neural basis of emotion regulation put forward the idea that men put less cognitive effort into analysing their emotional experiences and instead rely more on automatic emotion regulation, which means they have more difficulties in reflecting on and understanding their emotions (McRae et al. 2008). In contrast to other authors we found that women reported more difficulties with the non-acceptance of emotional responses than men (Gratz and Roemer 2004). Due to the automaticity in emotion regulation among men they might lack the ability for introspection and therefore cannot accurately report the acceptance or non-acceptance of their own emotions (McRae et al. 2008).

In accordance with previous literature this research found that greater difficulties in emotion regulation were positively correlated with driving errors, lapses, aggressive violations, and ordinary violations for both men and women (Arnau-Sabatés et al. 2012; Cerniglia et al. 2015; Harris and Nass 2011; Trógolo et al. 2014). These relationships are important for drivers of all age groups, as age was only weakly related to risky driving behaviour. The relationship between problems in dealing with emotions and risky driving might have several explanations. Firstly, an inability to control one's emotions in an appropriate way may lead to cognitive distortions that alter the rational decision making process during driving (Hu et al. 2013). Secondly, risk taking might serve as a coping strategy for people who cannot find other ways to control intense emotions (Cooper et al. 1995). Furthermore, this relationship might be significant due to variables that were not measured in this study, such as personality traits. Several authors have claimed that better emotion regulation and less frequent risk taking behaviour are indicators of certain personality characteristics (e.g., conscientious, emotional stability) (Clarke and Robertson 2005).

Structural equation modelling showed that difficulties in emotion regulation better account for aggressive violations and ordinary violations than they did for lapses and errors. This might be due to the different psychological origins of these different types of risky driving behaviours. Errors and lapses are thought to originate from disturbances in cognitive processes and information processing, while violations are deliberate decisions to take risk based on the individuals' motivational system (Lajunen and Özkan 2011). In such a case, the correlations between regulatory strategies and violations support the idea that emotions play an important role in human behaviour through motivational processes (Arnau-Sabatés et al. 2012; Hu et al. 2013). Furthermore, the significant relationships between errors, lapses and difficulties in emotional regulations may 
suggest that cognitive processing of emotions complicates the decision making process while driving, leading to an increase in errors and lapses (Hu et al. 2013).

It has to be noted that when controlling for any interactions between the distinct emotion regulation difficulties, violations, lapses, and errors were only explained by four of the emotion regulation subscales, despite six of the subscales having significant zero - order correlations. Interestingly, in the interactive model two types of difficulties (non-acceptance of emotional responses and limited strategies of emotional regulation) were negatively related to violations, whereas in the correlational analysis these were non-significant or positive correlations. Also a lack of emotional awareness and a lack of emotional clarity lost their explanatory value in the integrated model of risky driving. This means that non-acceptance of emotional responses, difficulties in impulse control, difficulties engaging in goal-directed behaviour and having limited access to emotion regulation strategies were more important predictors of the four types of risky driving on the road. A lack of emotional clarity and awareness might be influenced by one's introspection abilities, meaning that these difficulties do not frustrate the driver and thus do not manifest themselves in a driver's behaviour (McRae et al. 2008). Deficits in emotion regulation (e.g., difficulties engaging in goal-directed behaviour or impulse control problems) might demand more immediate regulative efforts, thus failure of self-control induces risky driving (Gratz and Roemer 2004; Gross 1999; Trógolo et al. 2014). Clearly such explanations are only exploratory and future research is needed to confirm these findings and to investigate the underlying mechanisms.

The present research has several limitations which should be taken into account when reading the results. Firstly, non-random sampling of participants means that it may not be possible to generalize these results to the wider population. Therefore, future research should replicate this study with a representative sample of Lithuanian drivers. Although the sample of the current study had sufficient age variation, it is slightly younger than the general population of Lithuanian drivers. Nevertheless, a number of our findings were consistent with those of previous research, which provides additional support for our data, e.g. gender and age differences in DBQ (Endriulaitienè et al. 2013; Rhodes and Pivik 2011; Özkan and Lajunen 2006). The main findings of the study confirmed our literature-based hypotheses, and therefore similar conclusions might be expected in another sample of Lithuanian drivers. Secondly, the cross-sectional nature of this study does not allow conclusions to be drawn regarding causation. A third problem is that the study relied exclusively on self - reported data and thus common method variance bias and socially desirable responding may have affected the findings. However, several researchers have reported that the DBQ is not significantly affected by social desirability bias (Lajunen and Summala 2003; Sullman and Taylor 2010). Lastly, the measure of emotion regulation (DERS) is relatively new in the risky driving context (Gratz and Roemer 2004; Trógolo et al. 2014), and more robust evidence regarding the scales validity and reliability in different countries and cultures is needed.

Despite the above limitations there are a number of practical implications which come from this study. The findings confirm that it is very important to consider drivers' emotion regulation abilities in order to understand and prevent risky driving behaviour. This may encourage the testing of drivers' fitness to drive, in terms of emotional readiness before the driver licensing process begins. These findings may also point towards the possibility to improve training programmes for pre-drivers and drivers by adding activities that contribute to the development of the most important emotional skills. Of course, such recommendations might be a challenge for driver trainers, as they will require special training to contribute effectively to the development of the individuals' emotional skills. In conclusion, the present data suggest that road safety interventions targeted at 
drivers' abilities to regulate emotion may help to prevent traffic injuries among drivers, irrespective of age or gender.

\section{ACKNOWLEDGEMENTS}

The authors would like to thank Diana Pekarskienè, who contributed to this study by surveying drivers and processing preliminary data.

\section{REFERENCES}

Arnau-Sabatés L, Sala-Roca J, Jariot-Garcia M. Emotional abilities as predictors of risky driving behaviour among a cohort of middle aged drivers. Accid Anal Prev. 2012;45:818-825.

Berking M, Margraf M, Ebert D, Wupperman P, Hofmann SG, Junghanns K. Deficits in emotion-regulation skills predict alcohol use during and after cognitive-behavioural therapy for alcohol dependence. $J$ Consult Clin Psych. 2011;79(3):307-318.

Butler EA, Lee TL, Gross JJ. Emotion regulation and culture: Are the social consequences of emotional suppression culture-specific? Emotion. 2007;7:30-48.

Cerniglia L, Cimino S, Ballarotto G, Casini E, Ferrari A, Carbone P, Cersosimo M. Motor vehicle accidents and adolescents: An empirical study on their emotional and behavioral profiles, defence strategies and parental support. Transport Res F-Traff. 2015;35:28-36.

Clarke S, Robertson IT. A meta-analytic review of the Big Five personality factors and accident involvement in occupational and non-occupational settings. J Occup Organ Psychol. 2005;78:355-376.

Cooper ML, Frone MR, Russell M, Mudar P. Drinking to regulate positive and negative emotions: a motivational model of alcohol use. J Per Soc Psychol. 1995;69(5):990-1005.

Di Stasi LL, Contreras D, Canas JJ, Cándido A, Maldonado A, Catena A. The consequences of unexpected emotional sounds on driving behaviour in risky situations. Safety Sci. 2010;48(10):1463-1468.

Dula CS, Geller ES. Risky, aggressive, or emotional driving: Addressing the need for consistent communication in research. J Safety Res. 2003;34:599-666.

Endriulaitienė A, Šeibokaitė L, Markšaitytė R, Žardeckaitė-Matulaitienė K, Pranckevičienė A. Lietuviu rizikingas vairavimas: ka gali paaiškinti psichologiniai veiksniai. Monograph (in Lithuanian). Kaunas, Lithuania: Versus Aureus; 2013:302.

Eurostat. Deaths due to transport accidents. 2015. Available at: http://ec.europa.eu/eurostat. Accessed September 20, 2016.

González-Iglesias B, Gómez-Fraguela JA, Luengo-Martín MÁ. Driving anger and traffic violations: Gender differences. Transport Res F-Traff. 2012;15(4):404-412.

Gratz KL, Roemer L. Multidimensional assessment of emotion regulation and dysregulation: Development, factor structure, and initial validation of the difficulties in emotion regulation scale. J Psychopathol Behav. 2004;26(1):41-54.

Gross J.J. Emotion regulation: Past, present, future. Cognition Emotion. 1999;13(5):551-573.

Harris H, Nass C. Emotion regulation for frustrating driving contexts. In Proceedings of the SIGCHI Conference on Human Factors in Computing Systems, ACM. 2011;May:749-752. 
Hu TY, Xie X, Li J. Negative or positive? The effect of emotion and mood on risky driving. Transport Res FTraff. 2013;16:29-40.

Jallais C, Gabaude C, Paire-Ficout L. When emotions disturb the localization of road elements: Effects of anger and sadness. Transport Res F-Traff. 2014;23:125-132.

Jeon M, Walker BN, Yim JB. Effects of specific emotions on subjective judgment, driving performance, and perceived workload. Transport Res F-Traff. 2014;24:197-209.

Lajunen T, Özkan T. Self-report instruments and methods. In E. Porter (Ed.). Handbook of Traffic Psychology, Elsevier Inc. 2011:43-59.

Lajunen T, Parker D, Summala H. The Manchester Driver Behaviour Questionnaire: a cross-cultural study. Accid Anal Prev. 2004;36:231-238.

Lajunen T, Parker D, Summala H. The Manchester Driver Behaviour Questionnaire: a cross-cultural study. Accid Anal Prev. 2004;36:231-238.

Lajunen T, Summala H. Can we trust self-reports of driving? Effects of impression management on driver behaviour questionnaire responses. Transport Res F-Traff. 2003;6:97-107.

Lavender JM, Green D, Anestis MD, Tull MT, Gratz KL. Negative affect, negative urgency, thought suppression, and bulimic symptoms: a moderated mediation analysis in a sample at-risk for bulimic symptoms. Eur Eat Disord Rev. 2015;23:246-250.

McRae K, Ochsner KN, Mauss IB, Gabrieli JJ, Gross JJ. Gender differences in emotion regulation: An fMRI study of cognitive reappraisal. Group Process Interg. 2008;11(2):143-162.

Mesken J, Lajunen T, Summala H. Interpersonal violations, speeding violations and their relation to accident involvement in Finland. Ergonomics. 2002;45:469-483.

Mesken J. Determinants and Consequences of Drivers Emotions. Leidschendam, Netherlands; 2006:169.

Mesquita B, Walker R. Cultural differences in emotions: A context for interpreting emotional experiences. Behav Res Ther. 2003;41(7):777-793.

Nesbit SM, Conger JC. Predicting aggressive driving behavior from anger and negative cognitions. Transport Res F-Traff. 2012;15(6):710-718.

Özkan T, Lajunen T, Chliaoutakis JE, Parker D, Summala H. Cross-cultural differences in driving behaviours: A comparison of six countries. Transport Res F-Traff. 2006a;9(3): 227-242.

Özkan T, Lajunen T, Summala H. Driver behaviour questionnaire: a follo-up study. Accid Anal Prev. 2006b;38:386-395.

Özkan T, Lajunen T. What causes the differences in driving between young men and women? The effects of gender roles and sex on young driver's driving behavior and self-assessment. Transport Res F-Traff. 2006;9:269-277.

Reason JT, Manstead ASR, Stradling SG, Baxter JS, Campbell K. Errors and violations on the road: a real distinction? Ergonomics. 33;10-11:1315-1332.

Rhodes N, Pivik K, Sutton M. Risky driving among young male drivers: The effects of mood and passengers. Transport Res F-Traff. 2015;28:65-76.

Rhodes N, Pivik K. Age and gender differences in risky driving: The roles of positive affect and risk perception. Accid Anal Prev. 2011;43:923-931. 
Roidl E, Frehse B, Oehl M, Höger R. The emotional spectrum in traffic situations: Results of two online-studies.

Transport Res F-Traff. 2013;18:168-188.

Stelmokienė A, Endriulaitienė A, Šeibokaitė L, Žardeckaitė-Matulaitienė K, Pranckevičienė A, Markšaitytė R. Lietuviškosios Vairuotojų elgesio klausimyno versijos psichometrinių rodiklių analizè. International Journal of Psychology: A Biopsychosocial Approach. 2013;13:139-158.

Sullman MJM, Meadows ML, Pajo K. Aberrant driving behaviours amongst New Zealand truck drivers. Transport Res F-Traff. 2002; 5:217-232.

Sullman MJM, Stephens AN, Zaporozhets T. Gender roles and the expression of driving anger amongst Ukrainian drivers. Risk Anal. 2016;10:1-13.

Sullman MJM, Taylor JE. Social desirability and self-reported driving avoidance: Should we be worried? Transport Res F-Traff. 2010;13:215-221.

Taubman - Ben-Ari O. The effects of positive emotion priming on self-reported reckless driving. Accid Anal Prev. 2012;45:718-725.

Trógolo MA, Melchior F, Medrano LA. The role of difficulties in emotion regulation on driving behavior. Journal of Behavior, Health \& Social Issues. 2014;6(1):107-117.

Williams F, Hasking P. Emotion regulation, coping and alcohol use as moderators in the relationship between non-suicidal self-injury and psychological distress. Prev Sci. 2010;11(1):33-41.

World Health Organization (WHO). Global Status Report on Road Safety: Time for Action. 2009. Available at: http://www.un.org/ar/roadsafety/pdf/roadsafetyreport.pdf. Accessed October 17, 2016.

World Health Organization (WHO). Ten facts on global road safety. 2015. Available at: http://www.who.int/features/factfiles/roadsafety/facts/en/. Accessed October 17, 2016. 
Table 1. Descriptive statistics and gender differences in difficulties of emotion regulation and risky driving

\begin{tabular}{|c|c|c|c|c|c|c|c|}
\hline Variable & Gender & $\mathrm{N}$ & Mean & SD & $\mathrm{t}$ & df & $\mathrm{p}$ \\
\hline \multirow{2}{*}{$\begin{array}{l}\text { Aggressive violations } \\
\text { (transformed value) }\end{array}$} & male & 117 & 1.6826 & .45941 & \multirow{2}{*}{5.358} & \multirow{2}{*}{243} & \multirow{2}{*}{$<.001$} \\
\hline & female & 128 & 1.4087 & .33599 & & & \\
\hline \multirow{2}{*}{ Ordinary violations } & male & 117 & 18.4701 & 6.91646 & \multirow{2}{*}{7.159} & \multirow{2}{*}{244} & \multirow{2}{*}{$<.001$} \\
\hline & female & 129 & 13.0698 & 4.81564 & & & \\
\hline \multirow{2}{*}{ Errors } & male & 116 & 12.0172 & 3.56061 & \multirow{2}{*}{1.465} & \multirow{2}{*}{231.207} & \multirow{2}{*}{.144} \\
\hline & female & 128 & 11.3828 & 3.16258 & & & \\
\hline \multirow{2}{*}{ Lapses } & male & 117 & 12.9316 & 3.75253 & \multirow{2}{*}{-.044} & \multirow{2}{*}{243.847} & \multirow{2}{*}{.965} \\
\hline & female & 129 & 12.9535 & 4.03667 & & & \\
\hline \multirow{2}{*}{$\begin{array}{l}\text { Non-acceptance of emotional } \\
\text { responses }\end{array}$} & male & 115 & 14.9478 & 4.98391 & \multirow{2}{*}{-2.121} & \multirow{2}{*}{239} & \multirow{2}{*}{.035} \\
\hline & female & 126 & 16.3016 & 4.91898 & & & \\
\hline \multirow{2}{*}{$\begin{array}{l}\text { Difficulties engaging in goal- } \\
\text { directed behaviour }\end{array}$} & male & 116 & 13.8362 & 4.80026 & \multirow{2}{*}{.652} & \multirow{2}{*}{241} & \multirow{2}{*}{.515} \\
\hline & female & 127 & 13.4488 & 4.46096 & & & \\
\hline \multirow{2}{*}{ Impulse control difficulties } & male & 116 & 12.9052 & 5.31442 & \multirow{2}{*}{.448} & \multirow{2}{*}{225.018} & \multirow{2}{*}{.654} \\
\hline & female & 127 & 12.6220 & 4.44352 & & & \\
\hline \multirow{2}{*}{ Lack of emotional awareness } & male & 116 & 11.5172 & 3.60551 & \multirow{2}{*}{3.073} & \multirow{2}{*}{241} & \multirow{2}{*}{.002} \\
\hline & female & 126 & 10.1339 & 3.41184 & & & \\
\hline \multirow{2}{*}{$\begin{array}{l}\text { Limited access to emotion } \\
\text { regulation strategies }\end{array}$} & male & 117 & 19.5812 & 6.01899 & \multirow{2}{*}{-.663} & \multirow{2}{*}{242} & 500 \\
\hline & female & 127 & 20.0709 & 5.52510 & & & .508 \\
\hline 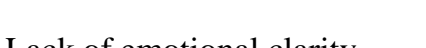 & male & 117 & 9.1709 & 3.51914 & 1205 & 211 & 164 \\
\hline Lack of emotional clarity & female & 126 & 9.8016 & 3.52141 & -1.395 & 241 & .104 \\
\hline
\end{tabular}


Table 2. Correlations between the emotion regulation and risky driving subscales

\begin{tabular}{|c|c|c|c|c|c|c|}
\hline Variable & $\begin{array}{l}\text { Non- } \\
\text { acceptance } \\
\text { of } \\
\text { emotional } \\
\text { responses }\end{array}$ & $\begin{array}{l}\text { Difficultie } \\
\text { s engaging } \\
\text { in goal - } \\
\text { directed } \\
\text { behaviour }\end{array}$ & $\begin{array}{l}\text { Impulse } \\
\text { control } \\
\text { difficulties }\end{array}$ & $\begin{array}{l}\text { Lack of } \\
\text { emotional } \\
\text { awareness }\end{array}$ & $\begin{array}{ll}\text { Limited access to } \\
\text { emotion regulation } \\
\text { strategies }\end{array}$ & $\begin{array}{l}\text { Lack of } \\
\text { emotional } \\
\text { clarity }\end{array}$ \\
\hline \multicolumn{7}{|l|}{ Males } \\
\hline $\begin{array}{l}\text { Aggressive } \\
\text { violations }\end{array}$ & .093 & $.467 * *$ & $.447 * *$ & .130 & $.299 * *$ & $.376 * *$ \\
\hline $\begin{array}{l}\text { Ordinary } \\
\text { violations }\end{array}$ & .091 & $.464 * *$ & $.432 * *$ & .113 & $.182 *$ & $.325 * *$ \\
\hline Errors & $.307 * *$ & $.444 * *$ & $.416 * *$ & -.035 & $.392 * *$ & $.324 * *$ \\
\hline Lapses & $.471 * *$ & $.523 * *$ & $.420 * *$ & -.032 & $.457 * *$ & $.318 * *$ \\
\hline \multicolumn{7}{|l|}{ Females } \\
\hline $\begin{array}{l}\text { Aggressive } \\
\text { violations }\end{array}$ & .027 & .046 & $.176^{*}$ & $.301 * *$ & .016 & .150 \\
\hline $\begin{array}{l}\text { Ordinary } \\
\text { violations }\end{array}$ & .150 & $.296 * *$ & $.229 * *$ & $.228 * *$ & .137 & $.187 *$ \\
\hline Errors & $.282 * *$ & $.240 * *$ & $.294 * *$ & $.303^{*}$ & $.286^{* * *}$ & $.267 * *$ \\
\hline Lapses & $.477 * *$ & $.426 * *$ & $.306 * *$ & $.174 *$ & $.457 * *$ & $.221 *$ \\
\hline
\end{tabular}




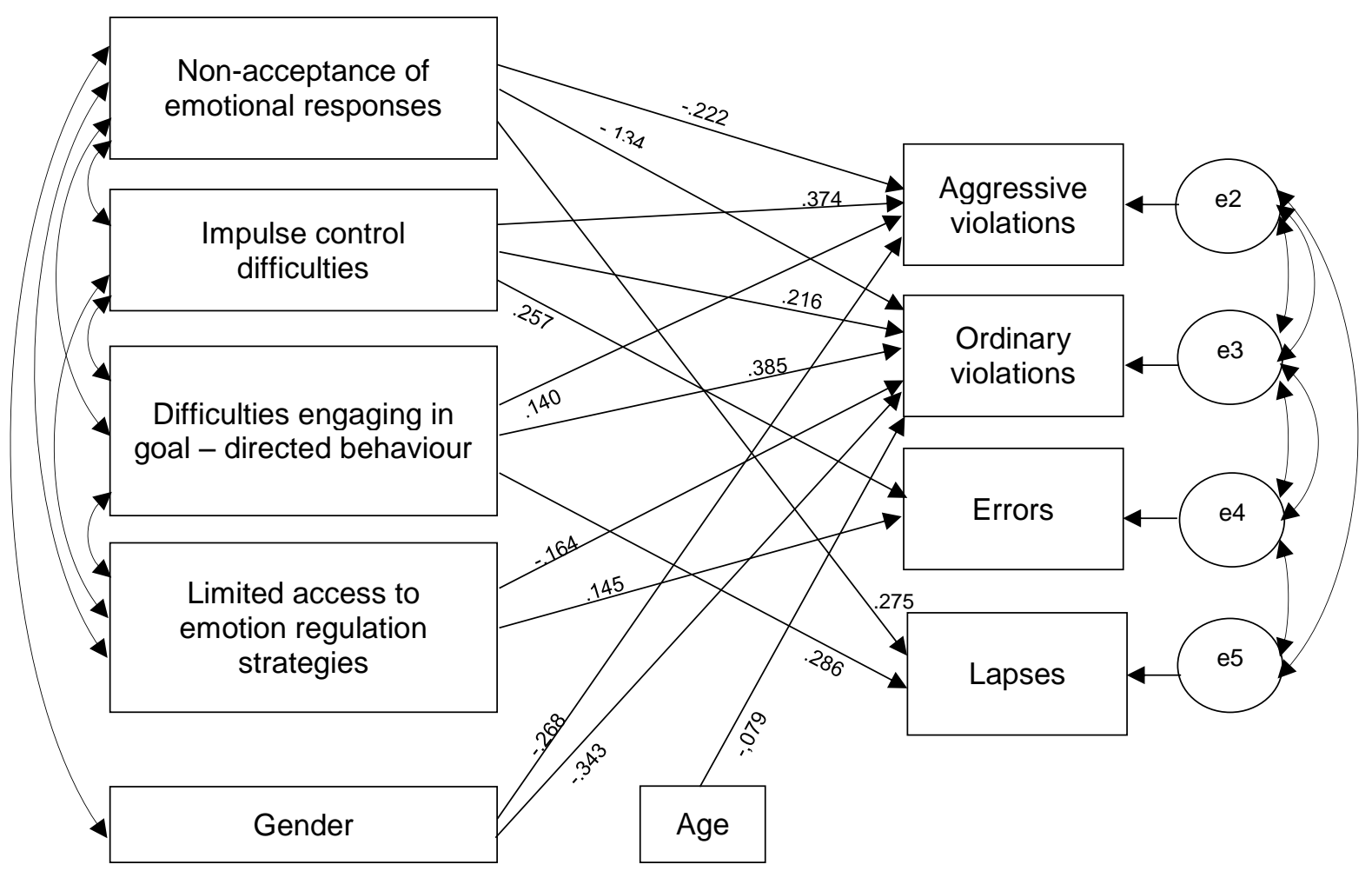

Figure 1. Structural equation model to explain the relationship between risky driving and difficulties in emotion regulation. 
2017-04-06

\section{Difficulties in emotion regulation and risky driving among Lithuanian drivers}

pÿ eibokait, L.

Taylor \& Francis

pÿLaura `eibokait, Auks Endriulaitien, Mark J.M. Sullman, Rasa Markaaityt, and Kristina pÿ\}ardeckait Matulaitien, Difficulties in emotion regulation and risky driving among Lithuanian drivers. Traffic Injury Prevention. 2017, Volume 18, Issue 7, pages 688-693

http://dx.doi.org/10.1080/15389588.2017.1315109

Downloaded from Cranfield Library Services E-Repository 